\title{
BMJ Open A structured exercise programme during haemodialysis for patients with chronic kidney disease: clinical benefit and long-term adherence
}

\author{
Kirsten Anding, ${ }^{1,2}$ Thomas Bär, ${ }^{1}$ Joanna Trojniak-Hennig, ${ }^{1}$ Simone Kuchinke, ${ }^{1}$ \\ Rolfdieter Krause, ${ }^{2}$ Jan M Rost, ${ }^{3,4}$ Martin Halle ${ }^{5,6,7}$
}

To cite: Anding K, Bär T, Trojniak-Hennig J, et al. A structured exercise programme during haemodialysis for patients with chronic kidney disease: clinical benefit and long-term adherence. BMJ Open 2015;5: 008709.

doi:10.1136/bmjopen-2015008709

- Prepublication history and additional material is available. To view please visit the journal (http://dx.doi.org/ 10.1136/bmjopen-2015008709)

Received 7 May 2015 Revised 16 July 2015 Accepted 31 July 2015

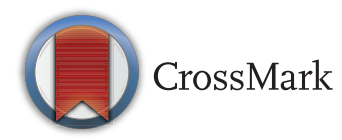

For numbered affiliations see end of article.

\section{Correspondence to} Dr Kirsten Anding; kirsten.anding-rost@ kfh-dialyse.de

\section{ABSTRACT}

Objective: Long-term studies regarding the effect of a structured physical exercise programme (SPEP) during haemodialysis (HD) assessing compliance and clinical benefit are scarce.

Study design: A single-centre clinical trial, nonrandomised, investigating 46 patients with $\mathrm{HD}(63.2$ \pm 16.3 years, male/female $24 / 22$, dialysis vintage 4.4 years) performing an SPEP over 5 years. The SPEP (twice/week for 60 min during haemodialysis) consisted of a combined resistance (8 muscle groups) and endurance (supine bicycle ergometry) training. Exercise intensity was continuously adjusted to improvements of performance testing. Changes in endurance and resistance capacity, physical functioning and quality of life (QoL) were analysed over 1 year in addition to long-term adherence and economics of the programme over 5 years. Average power per training session, maximal strength tests (maximal exercise repetitions/min), three performance-based tests for physical function, SF36 for QoL were assessed in the beginning and every 6 months thereafter.

Results: $78 \%$ of the patients completed the programme after 1 year and $43 \%$ after 5 years. Participants were divided-according to adherence to the programme-into three groups: (1) high adherence group ( $\mathrm{HA},>80 \%$ of 104 training sessions within 12 months), (2) moderate adherence (MA, $60-80 \%$ ), and 3. Low adherence group (LA, $<60 \%)$ ) with $\mathrm{HA}$ and MA evaluated quantitatively. One-year follow-up data revealed significant $(p<0.05)$ improvement for both groups in all measured parameters: exercise capacity (HA: $55 \%$, MA: $45 \%$ ), strength (HA: $>120 \%$, MA: $40-50 \%$ ), QoL in three scores of SF36 subscales and physical function in the three tests taken between $11 \%$ and $31 \%$. Moreover, a quantitative correlation analysis revealed a close association $(r=0.8)$ between large improvement of endurance capacity and weak physical condition (HA).

Conclusions: The exercise programme described improves physical function significantly and can be integrated into a HD routine with a high long-term adherence.

\section{Strengths and limitations of this study}

- This study shows for the first time that a structured, individual combined cardiovascular and resistance exercise programme during dialysis, suitable also for older and frail patients, can be permanently integrated into the dialysis routine of a standard dialysis unit.

- With patients' adherence maintained at the $80 \%$ level, the improvement of strength and endurance as well as quality of life over 1 year was significant and largest in very weak patients.

- With declining health status and sample size reduction due to death or transplantation, the size of the cohort was too small for quantitative analysis after 5 years.

- Owing to its study design with patient motivation being a key element, this single centre study did not allow for randomisation and a control group.

\section{INTRODUCTION}

Patients with end stage renal disease (ESRD) are characterised by low levels of physical activity and a continuous decline in physical function. Observational studies ${ }^{1-3}$ have revealed that physical inactivity is associated with increased mortality in these patients. Patients have a substantial and sustained decline in functional status, especially during the period before and after initiation of dialysis, in addition to a dramatically high mortality. ${ }^{4}$

Among the many reasons for low levels of physical activity in ESRD, three factors contribute most: (1) Reduced muscle strength caused by muscle catabolism and wasting, ${ }^{5-7}$ (2) a substantially increased cardiovascular risk in combination with a high prevalence of comorbid disorders, ${ }^{8}$ both leading to a reduced health related quality of life (QoL), ${ }^{9} 10$ which is in itself part of a vicious cycle further impairing physical activity with subsequently (3) reduced physical fitness. 
All these factors can be improved by exercise training: Aerobic endurance exercise training in patients with ESRD has been shown to improve physical functioning and QoL, ${ }^{11-21}$ data which have been previously reviewed. ${ }^{22-24}$ Also, resistance training has been proven to increase muscle strength and physical functioning in these patients. ${ }^{22} 25-27$ Moreover, exercise training improves cardiovascular risk factors such as blood pressure ${ }^{28} 29$ and lipid profiles ${ }^{30}$ as well as dialysis efficacy. ${ }^{31-33}$

Despite these proven benefits, a structured physical exercise programme (SPEP) for patients with dialysis is rarely performed on a routine basis. Even more scarce is regular exercise training during haemodialysis. This is surprising, as this approach offers a supervised setting for the patients, is time sparing as patients will not have to attend additional exercise sessions and even improves dialysis efficacy.

Therefore, empirical data on short-term and long-term follow-up including adherence and clinical benefit are mandatory to implement this approach in routine clinical practice. ${ }^{34-36}$ In our present study, we could demonstrate that this approach is indeed feasible and can be implemented in the daily dialysis routine. This, together with the quantitative evaluation of all data taken over the first year, constitutes the primary outcomes of the study, while the detailed adherence data after 5 years form the secondary outcome, allowing for an informed estimate for the boundary conditions of a future 5-year quantitative study (see online supplementary material).

\section{PARTICIPANTS AND METHODS}

\section{Participants}

Participants for the study were recruited from an outpatient haemodialysis unit $(\mathrm{KfH}$, Bischofswerda,
Germany), where they had been on maintenance haemodialysis for at least 3 months when starting the study. Patients were dialysed three times a week for $4-5 \mathrm{~h}$ and had to be in a stable medical condition (see table 1 for patient characteristics). Patients suffering from symptomatic ischaemic heart disease, orthopaedic or musculoskeletal problems interfering with exercise training were excluded. Forty six patients $(61 \%$ of all 72 patients in the unit at the beginning of the study, 24 male) were included.

\section{Study design}

The programme of combined endurance and resistance training (30 min each per training session, design is shown in figure 1) started after a 5 min warm-up and was performed twice a week during the first $2 \mathrm{~h}$ of dialysis under the direct supervision of an experienced exercise specialist. Regular maximal exercise tests provided new individual baseline parameters for the next training interval, namely maximal training heart and repetition rate for endurance and resistance, respectively.

\section{Endurance training}

Endurance training was performed with bed-cycle ergometers (MOTOmed letto2, Reck MOTOmed, Germany) positioned in front of the patients' chairs. Average power, total work and distance cycled, as well as the duration of each training session, were stored on a personalised memory card.

All patients were connected to a heart rate monitor with continuous registration during exercise. Each patient's target heart rate was calculated by Karvonen's method $^{37}$ from maximal exercise stress testing before inclusion in the study and stored on the memory card.

\begin{tabular}{|c|c|c|c|c|}
\hline Variable & $\begin{array}{l}\text { Group HA } \\
n=19\end{array}$ & $\begin{array}{l}\text { Group MA } \\
\mathrm{n}=12\end{array}$ & $\begin{array}{l}\text { Group LA and dropouts } \\
\mathrm{n}=15\end{array}$ & $\begin{array}{l}\text { Total } \\
\mathrm{n}=46\end{array}$ \\
\hline Age (years) & $63.4 \pm 13.8$ & $62.1 \pm 18.8$ & $63.9 \pm 18$ & $63.2 \pm 16.3$ \\
\hline Gender, male/female & $11 / 8$ & $6 / 6$ & $7 / 8$ & $24 / 22$ \\
\hline \multicolumn{5}{|l|}{ Comorbidities n (percentage) } \\
\hline Diabetes (\%) & $6(32)$ & $2(17)$ & $9(60)$ & $17(37)$ \\
\hline Hypertension (\%) & $17(89)$ & $11(92)$ & $15(100)$ & $43(94)$ \\
\hline Coronary artery disease (\%) & $7(37)$ & $3(25)$ & $7(47)$ & $17(37)$ \\
\hline Peripheral artery disease (\%) & $5(26)$ & $3(25)$ & $8(53)$ & $16(35)$ \\
\hline Cerebrovascular disease (\%) & $2(11)$ & $1(8)$ & $5(33)$ & $8(17)$ \\
\hline Heart failure (\%) & $3(16)$ & $3(27)$ & $7(47)$ & $13(28)$ \\
\hline Cancer (\%) & $4(21)$ & $2(18)$ & $3(20)$ & $9(20)$ \\
\hline Leg amputation & $1(5 \%)$ & 0 & $2(13 \%)$ & $3(7 \%)$ \\
\hline BMI $\left(\mathrm{kg} / \mathrm{m}^{2}\right)$ & $24.8 \pm 4.7$ & $27.6 \pm 7.0$ & $27.7 \pm 6.6$ & $27.1 \pm 5.6$ \\
\hline $\mathrm{Kt} / \mathrm{V}$ & $1.47 \pm 0.27$ & $1.58 \pm 0.3$ & $1.58 \pm 0.33$ & $1.54 \pm 0.3$ \\
\hline Dialysis vintage (years)* & $4(0.3,13)$ & $4.5(0.3,14)$ & $4(1,10)$ & $4.4(0.3,14)$ \\
\hline Haemoglobin (g/dL) & $11.52 \pm 1.14$ & $10.78 \pm 1.71$ & $11.3 \pm 1.42$ & $11.28 \pm 1.4$ \\
\hline Albumin (g/dL) & $39.93 \pm 4.82$ & $40.55 \pm 2.28$ & $38.24 \pm 3.77$ & $39.53 \pm 4.03$ \\
\hline
\end{tabular}


DYNAMIC RESISTANCE TRAINING

\section{ENDURANCE TRAINING}

\begin{tabular}{|c|c|c|c|}
\hline \multicolumn{2}{|c|}{$\begin{array}{l}12 \text { months regular training: } \\
60 \mathrm{~min} \text {, twice/week, }\end{array}$} & 8 exercises $^{a}$ & cycle ergometer ${ }^{b}$ \\
\hline \multirow[t]{2}{*}{ baseline test: } & & MRR (1 min) & RHR \& MHR \\
\hline & \multicolumn{3}{|c|}{ training intensity } \\
\hline month 1 & & $50 \%$ MRR & $0.5 \times($ MHR-RHR $)+R H R$ \\
\hline month $2 \& 3$ & & $65 \%$ MRR & $0.65 \times($ MHR-RHR) + RHR \\
\hline month $4 \& 5$ & & $70 \%$ MRR & $0.75 \times($ MHR-RHR $)+R H R$ \\
\hline \multirow[t]{2}{*}{$\begin{array}{l}\text { after month 5: } \\
\text { months 6-10: }\end{array}$} & \multicolumn{3}{|c|}{$\begin{array}{l}\text { repeat baseline test to get new MRR/MHR } \\
\text { as } 1-5 \text { but with new MRR/MHR, etc. }\end{array}$} \\
\hline & \multicolumn{2}{|c|}{$\begin{array}{l}\text { MRR: maximal repetition rate } \\
\text { achieved in baseline test }\end{array}$} & $\begin{array}{l}\text { HR: maximal heart rate during } \\
\text { initial maximal exercise test } \\
\text { IR: resting heart rate }\end{array}$ \\
\hline
\end{tabular}

Figure 1 Scheme for our individual structured training to improve endurance and strength in patients with dialysis including a feedback loop. (A) The eight exercises refer to the muscle groups biceps, triceps, abductor, adductor, abdomen, back, leg extensor and leg curl. Theraband resistance and weights were increased in relation to the patient's training success; for details, see text. (B) The training was performed with letto2 Reck MOTOmed cycle ergometers which record automatically the exercise data; see text.

The target heart rate was derived (see figure 1) from the maximum heart rate determined during the maximum exercise test: participants underwent maximal incremental exercise on a non-dialysis day using standard methodology by cycling $\geq 50 \mathrm{rpm}$ on an electrically braked ergometer (Ergo bike therapie 2000 pc; Daum electronic, Germany) with a three-lead ECG and blood pressure monitoring. The test starts with a workload of $10 \mathrm{~W}$, increasing by $10 \mathrm{~W}$ every $2 \mathrm{~min}$. Participants continue until muscular fatigue, pathological ECG criteria or new clinical symptoms appear.

\section{Resistance training}

Eight muscle groups were trained with an individual target repetition rate $(\mathrm{R})$ (see figure 1) of appropriate exercises in two sets of 1 min each with a 1 min break according to table 2. Biceps and triceps were trained with weights of $0.5,1.0,2.0$ and $4.0 \mathrm{~kg}$ according to the patient's strength. Similarly, for the abductor, elastic bands (theraband) with different resistances were used. Patients started with weights/therabands inducing a subjectively perceived intensity of 'somewhat hard'. For illustration, two short training videos are available as online supplementary material.

The target repetition rate was derived from the maximal repetition rate (MRR) in a maximum strength test for all eight muscle groups: Patients were asked to perform as many repetitions as possible in $1 \mathrm{~min}$.

Since we observed a faster increase in the patients' strength, in modification of the training programme according to figure 1, maximum strength tests for new baseline parameters and the corresponding training adaption were initiated after $3,5,7$ and 9 months. If the MRR exceeded $50 \mathrm{rpm}$, a heavier weight or a more rigid theraband with more resistance was used for the biceps/ triceps or abductor exercise.

\section{Clinical tests of physical mobility and capacity}

The improvement of physical function was assessed with three performance-based tests at baseline and subsequently every 6 months:

1. The 6 min walking test measures walking distance as a rough measure of maximal exercise capacity and was performed according to the American Thoracic Society. ${ }^{38}$

2. The timed up and go test is a short test which measures basic mobility skills. ${ }^{39}$

3. The sit to stand test (STS60) measures functional lower extremity strength during $60 \mathrm{s.}{ }^{40}$

\section{Quality of life}

QoL was assessed with the SF-36 survey ${ }^{41}$ at baseline and after 6 and 12 months.

\section{Motivation strategies}

Patients were exercising together during dialysis and were permanently motivated by the trainer, medical staff and physicians. The individual development of exercise

Table 2 Strength improvement through resistance training

\begin{tabular}{|c|c|c|c|c|c|c|c|c|}
\hline \multirow[b]{2}{*}{$\begin{array}{l}\left(R_{12} / R_{0}-1\right) \\
\pm S E(\%)\end{array}$} & \multicolumn{8}{|l|}{ Exercise } \\
\hline & leg extensor & $\begin{array}{l}\text { leg } \\
\text { curl }\end{array}$ & Back & adductor & abdomen & biceps & triceps & abductor \\
\hline Group HA & $89 \pm 15$ & $34 \pm 10$ & $112 \pm 31$ & $100 \pm 21$ & $140 \pm 32$ & $33 \pm 7.9$ & $47 \pm 11$ & $129 \pm 29$ \\
\hline p Value (ANOVA) & $<0.0001$ & 0.001 & 0.0004 & $<0.0001$ & $<0.0001$ & $<0.0001$ & $<0.0001$ & $<0.0001$ \\
\hline Group MA & $74 \pm 22$ & $48 \pm 30$ & $79 \pm 58$ & $61 \pm 32$ & $74 \pm 32$ & $16 \pm 15$ & $5.6 \pm 11$ & $43 \pm 16$ \\
\hline p Value (ANOVA) & 0.002 & 0.09 & 0.19 & 0.045 & 0.033 & 0.28 & 0.59 & 0.0007 \\
\hline
\end{tabular}

Strength improvement $R_{12} / R_{0}-1$ in per cent measured in maximum training tests of all muscles trained after 12 months with respect to initial strength. Groups characterise the degree of training participation, HA: $80-100 \%$, MA: $60-80 \%$. The significance level $p$ is also given. The exercises consisted of pressing one's legs against a big ball at the end of the chair/bed (leg extensor); positioning a big ball under the knees and squeezing it with one's heels (leg curl); hip bridge (back); pressing with a ball (adductor); crunches (abdomen); biceps curl (only non-shunt arm, patients were motivated to train the shunt arm between dialysis sessions); triceps extensions (non-shunt arm) with weights; abductors pulling with a theraband.

ANOVA, analysis of variance; HA, high adherence; MA moderate adherence. 
capacity and training data was discussed every 3 months with the patient as part of the treatment which also included the adaption of the prescribed exercise intensity.

\section{Statistics}

Quantitative analysis over 1 year was performed for patients who completed more than $60 \%$ of the 104 target training sessions of the first year. They were divided into high adherence (HA) and moderate adherence (MA) adherence groups with more than $80 \%$ and $60-80 \%$ of the sessions completed, respectively. These groups were evaluated separately to investigate the effect of high and moderate compliance on physical functions.

The third group, the low adherence group (LA, $<60 \%$ session participation), consisted of five members only, precluding follow-up evaluation due to very different comorbidities, for example, diabetes, peripheral artery disease, cardiovascular disease, chronic heart failure and leg amputation.

The effect of the resistance training was quantified by recording the repetitions $R_{N}$ of each exercise from the maximum exercise tests for each patient at the beginning of training and after 3, 5, 7, 9 and 12 months. The normalised data $R_{N} / R_{0}$ were compared statistically among patients to the initial value for $\mathrm{N}=0$, which is by construction unity. Results including the respective $\mathrm{p}$ values (analysis of variance, ANOVA) are summarised for patient groups HA and MA in table 2.

The success of the endurance training was assessed according to the power achieved in each training session, which was averaged over 1 month to give 12 data points $\mathrm{P}_{\mathrm{N}}$ over a year for each patient. The normalised power data $\mathrm{P}_{\mathrm{N}} / \mathrm{P}_{1}$ were compared statistically among patients to the initial value for $\mathrm{N}=1$. Resulting curves including the $\mathrm{p}$ values (ANOVA) are given for groups $\mathrm{HA}$ and $\mathrm{MA}$ in figure 2.

Additional analysis aimed at revealing a possible correlation between the change of power from 1 month to the next one, $\Delta \mathrm{P} / \Delta \mathrm{t}$, and the power $\mathrm{P}$ itself. In a typical saturation behaviour for the power, characterised by a logistic equation, $\Delta \mathrm{P} / \Delta \mathrm{t}$ is given by $\Delta \mathrm{P} / \Delta \mathrm{t}=\alpha \mathrm{P}\left(\mathrm{P}_{\infty}-\mathrm{P}\right)$, where $\alpha$ (in units of inverse Megajoule, $\mathrm{MJ}^{-1}$ ) characterises the patient's relative improvement in power for work done, while $\mathrm{P}_{\infty}$ specifies the maximally reachable power. The relative change $\mathrm{Y}(\mathrm{P})=\mathrm{P}^{-1} \cdot \Delta \mathrm{P} / \Delta \mathrm{t}$ fits a linear regression curve (with different slope $-\alpha$ ) for each patient (figure 3). The (linear) correlation of the slopes with the average patients' power $\langle\mathrm{P}\rangle$ is demonstrated in figure 4.

The QoL and physical performance tests were quantified with paired t test statistics.

\section{RESULTS}

Quantitative evaluation

Strength parameters improved linearly in patients with a high compliance rate (group HA) over the exercise

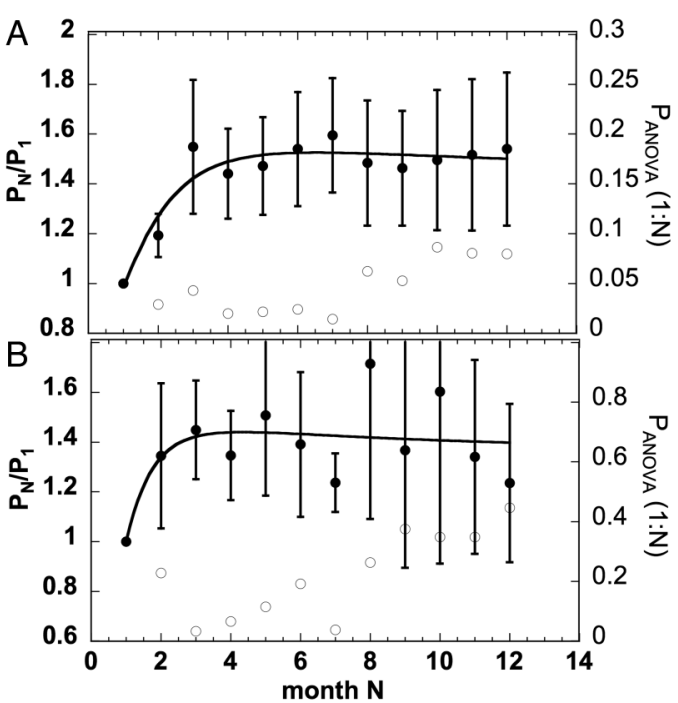

Figure 2 Endurance built through training on the cycle ergometer according to the scheme of figure 1. The power $P_{N}$ achieved on average in month $N$ is shown normalised to the power $\mathrm{P}_{1}$ in month $\mathrm{N}=1$. Data are taken from groups $\mathrm{HA}$ ( $>80 \%$ training participation) and MA $(60-80 \%$ training participation) for parts $(A)$ and $(B)$, respectively. The standard error is given for each data point as well as the significance $p$ (ANOVA) of $P_{N} / P_{1}$ being different from the initial value 1 at $\mathrm{N}=1$ with the scale on the right side. After month 3 , roughly the maximum average increase is reached $(55 \%$ and $45 \%$ in groups $\mathrm{HA}$ and MA, respectively). This corresponds to an average power of $\left\langle\mathrm{P}_{3}\right\rangle=22.1 \pm 2.0 \mathrm{~W}$ in group $\mathrm{HA}\left(\left\langle\mathrm{P}_{3}\right\rangle=19.4\right.$ $\pm 3.2 \mathrm{~W}$ in group MA) increased from an initial average power of $\left\langle\mathrm{P}_{1}\right\rangle=17.5 \pm 1.8 \mathrm{~W}$ and $\left\langle\mathrm{P}_{1}\right\rangle=16.0 \pm 3.0 \mathrm{~W}$ in groups $\mathrm{HA}$ and MA, respectively. ANOVA, analysis of variance; HA, high adherence; MA moderate adherence.

period at monthly rates from 3 to $10 \%$ for all eight muscle groups. The final results are listed in table 2. All improvements were highly significant $(\mathrm{p}<0.05)$.

However, the strength improved considerably less in patients with a lower compliance (group MA) whose

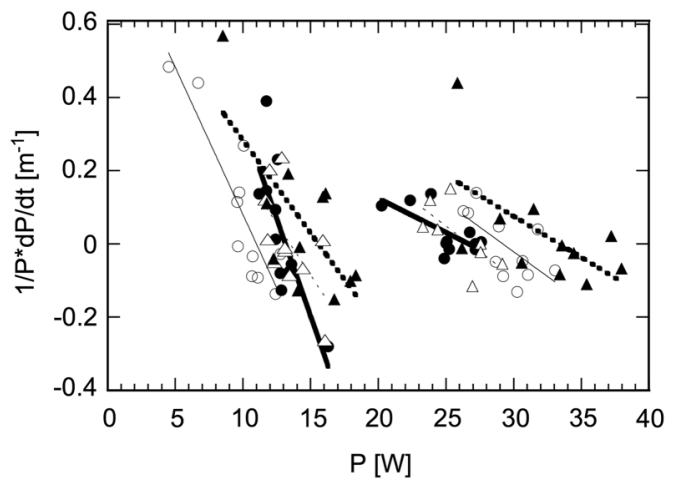

Figure 3 The relative rate of change in power $Y(P)=P^{-1} \cdot d P / d t$ in two successive months as a function of the power $\mathrm{P}$ itself. Shown are the data of four patients (group HA, $>80 \%$ training participation) with a mean power of $\angle P>\angle 15 \mathrm{~W}$ and four patients (group $\mathrm{HA}$ ) with $<\mathrm{P}>>25 \mathrm{~W}$ with individual linear regression fits. $\mathrm{HA}$, high adherence. 


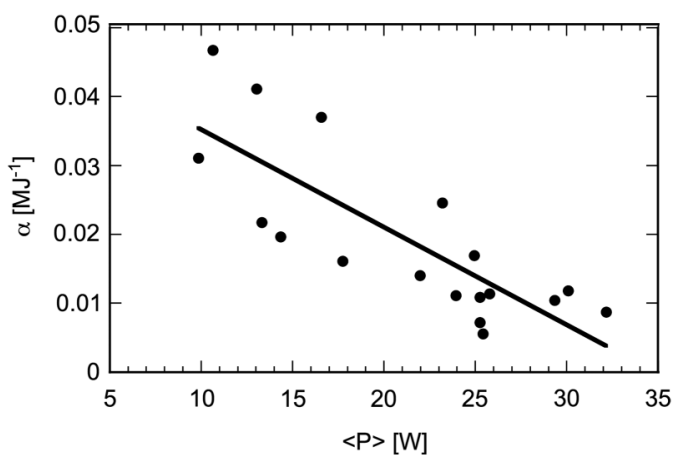

Figure 4 Correlation of the relative power improvement per work done, $\alpha\left(\mathrm{MJ}^{-1}\right)$, work measured in Megajoule (determined from the negative slopes of the linear regression fits as in figure 3 ), and the mean power $<P>$ for each patient from group HA. HA, high adherence.

average exercise volume was about $20 \%$ less as compared to group HA (see table 3). A significant increase $(\mathrm{p}<0.05)$ in repetitions in the maximum strengths tests was only achieved towards the end of the study after 12 months and only for some of the muscle groups, namely for the leg extensor, adductor, abdomen and abductor (see table 2).

Endurance exercise capacity measured in cycling power improved for groups $\mathrm{HA}$ and $\mathrm{MA}$ in parallel (figure 2). The maximal relative improvement was achieved after 3 months and amounts to a similar increase of $55 \%$ and $45 \%$ for groups HA and MA, respectively. Correspondingly, the average power achieved in groups HA and MA differs neither at the beginning of the training $\left(\left(<\mathrm{P}_{1}>=17.5 \pm 1.8 \mathrm{~W}\right.\right.$ vs $\left.\left.<\mathrm{P}_{1}\right\rangle=16.0 \pm 3.0 \mathrm{~W}\right)$ nor after 3 months $\left(<\mathrm{P}_{3}\right\rangle=22.1 \pm 2.0 \mathrm{~W}$ vs $\left.\left\langle\mathrm{P}_{3}\right\rangle=19.4 \pm 3.2 \mathrm{~W}\right)$. Between 3 and 12 months, the endurance capacity remained the same within statistical fluctuations, although with a slight trend to decrease as expected physiologically.

Figure 3 shows the relative change of power from 1 month to the next for patients from group HA, Y(P) $=\mathrm{P}^{-1} \cdot \mathrm{dP} / \mathrm{dt}$, plotted against the power itself. Patients with a high mean power have lower slopes $\mathrm{dY} / \mathrm{dP}$ (curves in the right part of the figure) than patients with a low mean power. In figure 4, we substantiate this observation by plotting the negative slopes $\alpha$ from the linear regression fits in figure 3 against each patient's mean power $\langle\mathrm{P}>$ over the 12-month period of quantitative evaluation. A clear correlation of $(\alpha,<\mathrm{P}>)$ emerges with a correlation coefficient of $r=0.80$ for the linear regression shown in figure 4 . The correlation implies that the improvement is higher in patients with a low baseline physical working capacity, a physiological phenomenon known from other conditions in healthy as well as diseased individuals. As we see here, it also holds for patients suffering from ESRD.

With the significant improvement of endurance and resistance measures, the physical function measured with three clinical tests of physical mobility improved significantly between $11 \%$ and $31 \%$, see table 4 . QoL parameters improved significantly in 4 (3) subscales of SF36 after 6 (12) months (see table 5).

Finally, we briefly comment on the five patients from the LA group ( $<60 \%$ adherence). These patients missed out on large parts of the training due to different reasons (see CONSORT statement in the online

Table 3 Patient exercise training participation

\begin{tabular}{|c|c|c|}
\hline & $\begin{array}{l}\text { After year } 1 \\
\mathrm{~N}(\%)\end{array}$ & $\begin{array}{l}\text { After year } 5 \\
\text { N (\%) }\end{array}$ \\
\hline Completers & $36(78 \%)$ & $20(43 \%)$ \\
\hline Group HA (80-100\% training participation) & $19(41 \%)$ & $15(33 \%)$ \\
\hline Mean training participation+SE (\%) & $87 \pm 5$ & $95 \pm 6$ \\
\hline Group $M A^{*}$ (60-80\% training participation) & $12(26 \%)$ & $2(4 \%)$ \\
\hline Mean training participation+SE (\%) & $71 \pm 6$ & $69 \pm 3$ \\
\hline Group LA† (<60\% training participation) & $5(11 \%)$ & $3(7 \%)$ \\
\hline Mean training participation+SE (\%) & $39 \pm 14$ & $10 \pm 13$ \\
\hline Dropouts & $10(22 \%)$ & $26(57 \%)$ \\
\hline Renal transplantation & - & $5(11 \%)$ \\
\hline Death (unrelated to study) & $5(11 \%)$ & $13(28 \%)$ \\
\hline Otherł & $5(11 \%)$ & $8(17 \%)$ \\
\hline Total & $46(100 \%)$ & $46(100 \%)$ \\
\hline
\end{tabular}

'Completers' still participated in the training programme after $1 / 5$ years. Training participation is given over a full period of 12 months in years 1 and 5, respectively. Groups HA and MA are used for quantitative evaluation after the first year, and training evolution was monitored in all groups: Out of the $\mathrm{N}=15$ patients of group HA in year 5,5 (2) patients belonged to group MA (LA) in year 1. From the two patients in group MA in year 5, 1 patient belonged to group LA in year 1. From the three patients in group LA (year 5), 1 (2) patient(s) belonged to group HA (MA) in year 1.

${ }^{*}$ Forced breaks of participation due to different medical problems.

†Reduced participation due to long hospitalisation (3 patients), long vacation (1) and lack of motivation (1).

$\ddagger$ Orthopaedic/arthritic (4), psychological problems (1), move to another city(1), lack of motivation (2).

HA, high adherence; LA, low adherence; MA moderate adherence. 
Table 4 Clinical tests of physical mobility

\begin{tabular}{llllll}
\hline & Baseline & After $\mathbf{6}$ months & After $\mathbf{1 2}$ months & p $\mathbf{0}$ vs $\mathbf{6}$ months & p $\mathbf{0}$ vs 12 months \\
\hline Timed up and go test $(\mathrm{s})$ & $10.1 \pm 4.0$ & $9.1 \pm 3.5$ & $7.5 \pm 2.8$ & 0.002 & $<0.0001$ \\
Sit to stand test (repetitions/min) & $16.7 \pm 8.3$ & $20.5 \pm 8.8$ & $24.2 \pm 10.2$ & 0.0053 & $<0.0001$ \\
Six minute walk test $(\mathrm{m})$ & $360 \pm 132$ & $374 \pm 134$ & $403 \pm 141$ & $\mathrm{NS}$ & 0.0002 \\
\hline
\end{tabular}

Only patients who completed all three test-series (24 of 36 patients who completed the first year, all patients from groups HA/MA)

were analysed. Data are expressed as mean \pm SE.

$\mathrm{HA}$, high adherence; MA moderate adherence.

supplementary material) and the scarce data taken show that the spread of the mean power achieved in endurance training varies by a factor of 8 between the five patients. Most importantly, none of the LA group members showed a significant improvement over the 12 months, either in endurance or in resistance training. After year 5, two of these patients were forced dropouts (one died and the other moved). The fact that the residual three patients were still exercising in year 5 (2 in the HA group and 1 in the MA group, see caption table 3) is an indication-statistically not provable-of training benefit even for initially LA patients.

\section{Costs for training}

In a dialysis shift with exercise training, professional exercise supervision is needed for $2 \mathrm{~h}$ corresponding to a $0.1(0.14)$ full time equivalent for training twice (three times) a week. In each shift, a maximum of three exercising patients can share a bike. Executed in this way, each training session costs approximately $€ 8 /$ patient, which includes financing and maintenance of the bikes.

\section{Adherence}

Thirty six patients were still exercising after 1 year and 20 patients after 5 years. Patients' SPEP participation as well as average training intensity is shown in table 3 . Only 10 of the 20 patients completing 5 years of training remained in stable clinical conditions during the whole study period. The other 10 patients had major medical problems, namely myocardial infarction (2 patients), serious infections (5 patients) or major operations (3 patients). The 20 patients still participating in the programme after 5 years were $68 \pm 13.9$ years old compared to the average of $63.2 \pm 16.3$ years for all 46 patients at the beginning of the study. This implies that there is no bias in the age distribution of the 26 patients which terminated the SPEP. Among them were 21 forced dropouts (13 patients died and 5 were transplanted) leaving 8 $(17 \%)$ unforced dropouts over 5 years, yielding an adherence rate of over $80 \%$.

\section{DISCUSSION}

\section{Principal findings and comparison with other studies}

Our individually tailored and supervised SPEP during haemodialysis led to a striking and statistically highly significant improvement in strength and endurance in the participating patients over 1 year. This was accompanied by an improved QoL assessed by the SF36 questionnaire (in the subscales of physical functioning, role of physical/emotional limitations).

The unforced dropout rate of $11 \%$ in the first year (the other $11 \%$ dropout patients died) was substantially lower compared to previous studies, for example, by DePaul et $a l^{17}$ with $50 \%$ dropouts after 5 months, by Mercer $e t a l^{16}$ with $52 \%$ dropouts after 3 months, and by Miller $e t a t^{28}$ with $60 \%$ dropouts after 6 months. We attribute this to our combined endurance and resistance training scheme during haemodialysis with moderate intensity in combination with a number of organisational measures to enhance the motivation for training. The quantitative improvement of strength in our patients is comparable to results reported in other studies. van Vilsteren et $a l^{14}$ demonstrated an improvement of the lower extremities in functional tests after 3 months with combined endurance/resistance training.

\section{Table 5 Quality of life}

\begin{tabular}{|c|c|c|c|c|c|}
\hline & Baseline & After 6 months & After 12 months & p 0 vs 6 months & p 0 vs 12 months \\
\hline Physical functioning & $53 \pm 37$ & $60 \pm 37$ & $58 \pm 39$ & 0.004 & 0.048 \\
\hline Role of physical limitations & $35 \pm 48$ & $50 \pm 50$ & $46 \pm 50$ & 0.005 & 0.033 \\
\hline Role of emotional limitations & $51 \pm 50$ & $72 \pm 45$ & $66 \pm 48$ & $<0.0001$ & 0.003 \\
\hline Vitality & $45 \pm 21$ & $50 \pm 22$ & $50 \pm 27$ & NS & NS \\
\hline Mental health & $62 \pm 24$ & $67 \pm 24$ & $65 \pm 27$ & 0.014 & NS \\
\hline Social functioning & $67 \pm 27$ & $72 \pm 29$ & $58.06 \pm 34.70$ & NS & NS \\
\hline Pain & $59 \pm 28$ & $60 \pm 28$ & $56 \pm 32$ & NS & NS \\
\hline General health perception & $50 \pm 27$ & $53 \pm 26$ & $42 \pm 28$ & NS & NS \\
\hline
\end{tabular}


Likewise, Oh-Park et $a l^{15}$ found an improved one repetition maximum of knee extension, and Johansen et $a l^{25}$ described an increased muscular strength of the quadriceps muscles. In the study by Headley $e t a l,{ }^{27}$ a 12 -week resistance exercise training revealed a relatively small increase of strength in the leg extensors $(+12.7 \%)$, and Castaneda $e t a l^{26}$ showed an improvement of average strength by $32 \%$ (one repetition maximum, different muscles) over 12 weeks compared to a decline of $13 \%$ in the control group who did not exercise.

It has to be emphasised that our patients trained eight muscle groups continuously while in most other studies either the muscles were not specified explicitly or only a single group was trained. Interestingly, the improvements observed in our study are rather different between endurance and strength: For strength, the improvement is directly related to the amount of training which becomes obvious from table 2 when comparing results for HA group and the MA group MA. This conclusion is underlined by the finding that the leg extensor is the only exercise of the MA group showing a similar significant improvement over the year as for the HA group, which can be attributed to the fact that the leg extensor is simultaneously trained in the endurance training protocol during cycling.

The endurance improvement, on the other hand, showed no statistically significant difference between the groups (figure 2). Therefore, it may be concluded that endurance training twice a week with more than $60 \%$ participation over a year is sufficient to achieve the improvement documented. The endurance results also underline that the two groups HA and MA do not differ in their mean physical condition as both groups had a comparable mean age and number of comorbidities (see table 1).

The slight (statistically non-significant) decline after the maximum at month 3 (figure 2) has several reasons: For group HA, the key factor is motivation: it is hard to keep up over many months, in particular since the training success basically stalls after the third month. This is also corroborated by the result of the SF36 questionnaire, which reveals a slight decrease in the QoL in the second half of the year (in the subscales role of physical/emotional limitations, see table 5). Group MA shows along with a slight decline increasing spreading of the average power towards the end of the study year, indicated by the SE in figure 2B. Here, medical factors, unrelated to the training, often play a role and lead to an unsteady evolution of the power data in time. Therefore, the power $\mathrm{P}_{12}$ achieved after month 12 in group MA does not differ significantly from $P_{1}$ at the beginning of the training, despite the fact that the average level of power has been almost constant from $\mathrm{P}_{3}$ to $\mathrm{P}_{12}$.

In comparison, Storer $e t a t^{42}$ trained 12 patients over 10 weeks and increased the workload from $19 \pm 9 \mathrm{~W}$ to 29 $\pm 25 \mathrm{~W}$ at the end of their study. However, only $66 \%$ of the patients completed this ambitious programme. With a mean age of 44 years, they were about 20 years younger than our patients and were training three times a week. While the absolute increase in power at which our patients cycled at the end of the study was much lower $(20.8 \pm 2.6 \mathrm{~W})$, the relative increase by $50 \%$ was basically the same. In a number of studies, the change in $\mathrm{VO}_{2}$ peak is measured to assess the success of endurance training. Although the relation to improvement in physical performance or QoL is not yet firmly established, ${ }^{43}$ the $\mathrm{VO}_{2}$ peak increased similarly with endurance exercise as the power, namely by $36 \%$ in 1 year, ${ }^{44}$ $22 \%$ in 10 weeks $^{42}$ and $23 \%$ in 6 months. ${ }^{21}$

Finally, the correlation between the baseline physical condition and the effect of endurance training is an important finding. In reference ${ }^{45}$ it was concluded from SF-36 answers in connection with physical function tests that patients with low physical function show a larger improvement by endurance training than those with higher physical function. Complementarily, but along the same lines, DePaul et $a l^{17}$ concluded that patients with high physical function show a dichotomic behaviour, with no significant improvement in their health status, but improved physical impairment measures. Our analysis of $\alpha(\mathrm{M} / \mathrm{J})$, the relative improvement of power per work done, shows a clear anticorrelation with each patient's mean power $\langle\mathrm{P}>$ over the entire study time of 12 months in figure 4 . Indeed, this implies that physically weak patients $($ low $<\mathrm{P}>$ ) have a higher improvement rate (larger $\alpha$ ) than stronger patients, a finding also known from intervention trials in healthy individuals.

We regard it as a tremendous success that after 5 years still about half of the patients participated in the SPEP with only $17 \%$ unforced dropouts (table 3 ). To the best of our knowledge, there is only one published study on long-time adherence over 4 years of intradialytic training $^{44}$ with initially 24 patients who were on average 53 years old. The low number of forced dropouts (only one patient died in 4 years), together with the relatively low average age, points to a pre-selection of patients rendering the comparison to our study difficult. Interpreting the remaining four dropouts as unforced and therefore relevant to determine the adherence, their percentage of $17 \%$ is also comparable to our unforced dropout rate (over a 20\% longer time span, namely 5 years) of $17 \%$ (see table 3 ).

\section{Limitations of study and future research}

The study was non-randomised so that comparison for non-exercising patients with haemodialysis cannot be drawn. Although data on the long-term effect of SPEPs are crucial, it is difficult to assess this long impact quantitatively due to the changing and in general declining health status of the patients with time. As a consequence, participating patients' training habits significantly vary over 5 years, reflected in their changing assignments to the different groups (table 3). This is also the main reason why we have presented a quantitative evaluation in this single-centre study only over 
1 year. Future study designs could differentiate the patients according to one group with a stable physical condition during the study and the rest of the participating patients. On the basis of our results, we estimate that for a quantitative study evaluating $\mathrm{N}$ patients over 5 years, one needs an initial collective of $\mathrm{N}_{\text {tot }}=14.4 \mathrm{~N}$ patients, where the factor 14.4 results from various losses. With $\mathrm{N}_{\text {tot }}$ corresponding to $100 \%$, voluntary participation gives a reduction to $64 \%$, and death ${ }^{\mathrm{i}}$ and other dropout reasons a further reduction by $78.3 \%$. Finally, sufficient clinical stability to allow for quantitative training data over the entire 5 years was only given in $50 \%$ of the remaining patients. From our results, we predict that $\mathrm{N}=30$ is sufficient with a suitable study design (slightly modified in comparison with the present one). This brings $\mathrm{N}_{\text {tot }}$ to 432 , which appears to be feasible for a multicentre study. Details of the estimate can be found in the online supplementary material.

The ultimate criterion for the effect of SPEPs is a reduced mortality rate, which can be reliably determined over a long time span only in a much larger patient collective including a control group. This design should be realised in a multicentre study for which the present work has laid the foundation and has established a feasible and safe intervention programme.

\section{CONCLUSIONS}

In conclusion, we have developed and tested a combined cardiovascular and resistance personalised exercise programme, which can be integrated into normal dialysis care. Patients' strength and endurance as well as QoL improved significantly over a 1-year period and adherence was close to $80 \%$ after 5 years, correcting for the forced dropouts related to transplantation or death. To the best of our knowledge, this is the first time that an SPEP was successfully performed over half a decade. Exercise training for patients with dialysis should be seen as a main strategy aside from pharmacological therapy and dialysis. It has to be titrated similarly as the dose of medication. For any medication or intervention to be effective, the patient's adherence is crucial. In addition, for widespread application, it must be recognised by the health insurance system. Our SPEP as described here fulfils these four criteria: Each patient receives a personally adapted training programme including the mode and dose. The adherence is boosted by collective training and a stimulating environment created in the dialysis unit. Last but not least, the improvement of QoL of the patients contributes to the motivation for continued or even intensified exercise training. Support of this exercise training by a German health insurance company with $€ 8 /$ patient/training session covers the

${ }^{\mathrm{i}}$ Since the mortality rate among our participating patients was unusually low, we use here the average between our rate and the published rate from DOPPSdata, see Supplementary Material. direct costs and also contributes to the patients' motivation.

\section{Author affiliations}

${ }^{1} \mathrm{KfH}$ Kidney Center, Bischofswerda, Germany

${ }^{2}$ ReNi-German Society of Sports Rehabilitation in CKD, Berlin, Germany

${ }^{3}$ Max Planck-Institute for the Physics of Complex Systems, Dresden, Germany

${ }^{4}$ PULSE Institute, Stanford University, Palo Alto, USA

${ }^{5}$ Department of Prevention, Rehabilitation and Sports Medicine, Klinikum rechts der, Isar, Technische Universität München, Munich, Germany

${ }^{6}$ Partner site Munich Heart Alliance, DZHK (German Center for Cardiovascular

Research), Munich, Germany

${ }^{7}$ Else-Kröner-Fresenius-Zentrum, Munich, Germany

Acknowledgements The authors thank all patients for their long-term participation in the study and the dialysis team of the Nierenzentrum Bischofswerda for their continuous support, which was crucial for finalising this study. This study has been accepted as an oral presentation at the 52nd ERA-EDTA Congress, held by the European Renal Association in partnership with the UK- Renal Association London May 28-31, 2015.

Contributors KA initiated the study, whereas $\mathrm{KA}$ and $\mathrm{MH}$ designed the study. TB and JT-H were responsible for the roll-out of the exercise programme in the dialysis unit. TB, JT-H and SK performed the constant acquisition of patient data (personal data and training data). JMR performed the analysis of patient data. KA, JMR and MH drafted the manuscript, whereas RK revised it critically. All authors made critical comments, suggestions and revisions to earlier drafts. All authors interpreted the results and approved the final version of the paper. KA is the guarantor.

Funding This study was funded by the "Curatorium for dialysis and renal transplantation" (KfH, non-profit dialysis provider) for the first 3 years, since January 2013 the expenses of training have been taken over by a German health insurance company (AOKPlus Krankenkasse: https://www. aokplus-online.de/presse/pressemitteilungen/einzelansicht/fuer-mehrlebensqualitaet-aok-plus-bietet-ab-sofort-sporttherapie-waehrend-der-dialyse. $\mathrm{html})$. At the beginning of the study cycle, ergometers were supplied by Reck MOTOmed (RECK-Technik GmbH \& Co. KG, Betzenweiler, Germany). The KfH, the AOKPlus and Reck MOTOmed did not have any role in the study concept, design, data analysis or writing of the manuscript.

Competing interests None declared.

\section{Patient consent Obtained.}

Ethics approval The study was approved by the Ethics Committee at the Saxony Physician Chamber (Sächsische Landesärztekammer) Dresden, Germany (protocol \# EK-BR-45/08-1). All participants gave informed consent before starting the study.

Provenance and peer review Not commissioned; externally peer reviewed.

Data sharing statement No additional data are available.

Open Access This is an Open Access article distributed in accordance with the Creative Commons Attribution Non Commercial (CC BY-NC 4.0) license, which permits others to distribute, remix, adapt, build upon this work noncommercially, and license their derivative works on different terms, provided the original work is properly cited and the use is non-commercial. See: http:// creativecommons.org/licenses/by-nc/4.0/

\section{REFERENCES}

1. Beddhu S, Baird BC, Zitterkoph J, et al. Physical activity and mortality in chronic kidney disease (NHANES III). Clin J Am Soc Nephrol 2009;4:1901-6.

2. Tentori F, Elder SJ, Thumma J, et al. Physical exercise among participants in the Dialysis Outcomes and Practice Patterns Study (DOPPS): correlates and associated outcomes. Nephrol Dial Transplant 2010;25:3050-62.

3. Lopes AA, Lantz B, Morgenstern $\mathrm{H}$, et al. Associations of selfreported physical activity types and levels with quality of life, 
depression symptoms, and mortality in hemodialysis patients: the DOPPS. Clin J Am Soc Nephrol 2014;9:1702-12.

4. Kurella TM, Covinsky KE, Chertow GM, et al. Functional status of elderly adults before and after initiation of dialysis. $N$ Engl J Med 2009;361:1539-47.

5. Painter $P$. Physical functioning in end-stage renal disease patients: update 2005. Hemodial Int 2005;9:218-35.

6. Kettner-Melsheimer A, Weiss M, Huber W. Physical work capacity in chronic renal disease. Int J Artif Organs 1987;10:23-30.

7. Johansen KL, Doyle J, Sakkas GK, et al. Neural and metabolic mechanisms of excessive muscle fatigue in maintenance hemodialysis patients. Am J Physiol Regul Integr Comp Physiol 2005;289:R805-13.

8. Sarnak MJ, Levey AS. Cardiovascular disease and chronic renal disease: a new paradigm. Am J Kidney Dis 2000;35(4 Suppl 1): S117-131.

9. Finkelstein FO, Wuerth D, Finkelstein $\mathrm{SH}$. Health related quality of life and the CKD patient: challenges for the nephrology community. Kidney Int 2009;76:946-52.

10. Kimmel PL, Patel SS. Quality of life in patients with chronic kidney disease: focus on end-stage renal disease treated with hemodialysis. Semin Nephrol 2006;26:68-79.

11. Kopple JD, Storer T, Casburi R. Impaired exercise capacity and exercise training in maintenance hemodialysis patients. J Ren Nutr 2005; 15:44-8.

12. Painter $\mathrm{P}$, Zimmerman SW. Exercise in end-stage renal disease. $A m$ $J$ Kidney Dis 1986;7:386-94.

13. Painter $P$. Determinants of exercise capacity in CKD patients treated with hemodialysis. Adv Chronic Kidney Dis 2009;16:437-48.

14. van Vilsteren MC, de Greef MH, Huisman RM. The effects of a lowto-moderate intensity pre-conditioning exercise programme linked with exercise counselling for sedentary haemodialysis patients in The Netherlands: results of a randomized clinical trial. Nephrol Dial Transplant 2005;20:141-6.

15. Oh-Park M, Fast A, Gopal S, et al. Exercise for the dialyzed: aerobic and strength training during hemodialysis. Am J Phys Med Rehabil 2002;81:814-21.

16. Mercer TH, Crawford C, Gleeson NP, et al. Low-volume exercise rehabilitation improves functional capacity and self-reported functional status of dialysis patients. Am J Phys Med Rehabil 2002;81:162-7.

17. DePaul V, Moreland J, Eager T, et al. The effectiveness of aerobic and muscle strength training in patients receiving hemodialysis and EPO: a randomized controlled trial. Am J Kidney Dis 2002;40:1219-29.

18. Moinuddin I, Leehey DJ. A comparison of aerobic exercise and resistance training in patients with and without chronic kidney disease. Adv Chronic Kidney Dis 2008;15:83-96.

19. Daul AE, Schafers RF, Daul K, et al. Exercise during hemodialysis. Clin Nephrol 2004;61(Suppl 1):S26-30.

20. Johansen KL. Exercise and dialysis. Hemodial Int 2008;12:290-300.

21. Painter $\mathrm{P}$, Moore $\mathrm{G}$, Carlson $\mathrm{L}$, et al. Effects of exercise training plus normalization of hematocrit on exercise capacity and health-related quality of life. Am J Kidney Dis 2002;39:257-65.

22. Heiwe S, Jacobson SH. Exercise training in adults with CKD: a systematic review and meta-analysis. Am J Kidney Dis 2014:64:383-93.

23. Heiwe $\mathrm{S}$, Jacobson $\mathrm{SH}$. Exercise training for adults with chronic kidney disease. Cochrane Database Syst Rev 2011;(10):CD003236.

24. Smart N, Steele M. Exercise training in haemodialysis patients: a systematic review and meta-analysis. Nephrology (Carlton) 2011:16:626-32.

25. Johansen KL, Painter PL, Sakkas GK, et al. Effects of resistance exercise training and nandrolone decanoate on body composition and muscle function among patients who receive hemodialysis: a randomized, controlled trial. J Am Soc Nephrol 2006;17:2307-14.

26. Castaneda C, Gordon PL, Uhlin KL, et al. Resistance training to counteract the catabolism of a low-protein diet in patients with chronic renal insufficiency. A randomized, controlled trial. Ann Intern Med 2001;135:965-76.

27. Headley S, Germain M, Mailloux P, et al. Resistance training improves strength and functional measures in patients with endstage renal disease. Am J Kidney Dis 2002;40:355-64.

28. Miller BW, Cress CL, Johnson ME, et al. Exercise during hemodialysis decreases the use of antihypertensive medications. Am J Kidney Dis 2002;39:828-33.

29. Anderson JE, Boivin MR Jr, Hatchett $L$. Effect of exercise training on interdialytic ambulatory and treatment-related blood pressure in hemodialysis patients. Ren Fail 2004;26:539-44.

30. Goldberg AP, Geltman EM, Gavin JR III, et al. Exercise training reduces coronary risk and effectively rehabilitates hemodialysis patients. Nephron 1986;42:311-16.

31. Kirkman DL, Roberts LD, Kelm M, et al. Interaction between intradialytic exercise and hemodialysis adequacy. Am J Nephrol 2013;38:475-82.

32. Vaithilingam I, Polkinghorne KR, Atkins RC, et al. Time and exercise improve phosphate removal in hemodialysis patients. Am J Kidney Dis 2004;43:85-9.

33. Kong CH, Tattersall JE, Greenwood RN, et al. The effect of exercise during haemodialysis on solute removal. Nephrol Dial Transplant 1999;14:2927-31.

34. Williams AD, Fassett RG, Coombes JS. Exercise in CKD: why is it important and how should it be delivered? Am J Kidney Dis 2014;64:329-31.

35. Capitanini A, Lange S, D'Alessandro C, et al. Dialysis exercise team: the way to sustain exercise programs in hemodialysis patients. Kidney Blood Press Res 2014;39:129-33.

36. Bennett PN, Breugelmans L, Barnard R, et al. Sustaining a hemodialysis exercise program: a review. Semin Dial 2010;23:62-73.

37. Goldberg L, Elliot DL, Kuehl KS. Assessment of exercise intensity formulas by use of ventilatory threshold. Chest 1988;94:95-8

38. Kono K, Nishida $\mathrm{Y}$, Moriyama $\mathrm{Y}$, et al. Investigation of factors affecting the six-minute walk test results in hemodialysis patients Ther Apher Dial 2014;18:623-7.

39. Steffen TM, Mollinger LA. Age- and gender-related test performance in community-dwelling adults. J Neurol Phys Ther 2005;29: $181-8$.

40. Segura-Orti E, Martinez-Olmos FJ. Test-retest reliability and minimal detectable change scores for sit-to-stand-to-sit tests, the six-minute walk test, the one-leg heel-rise test, and handgrip strength in people undergoing hemodialysis. Phys Ther 2011;91:1244-52.

41. Hays RD, Morales LS. The RAND-36 measure of health-related quality of life. Ann Med 2001;33:350-7.

42. Storer TW, Casaburi R, Sawelson S, et al. Endurance exercise training during haemodialysis improves strength, power, fatigability and physical performance in maintenance haemodialysis patients. Nephrol Dial Transplant 2005;20:1429-37.

43. Johansen KL. Exercise and chronic kidney disease: current recommendations. Sports Med 2005;35:485-99.

44. Kouidi E, Grekas D, Deligiannis A, et al. Outcomes of long-term exercise training in dialysis patients: comparison of two training programs. Clin Nephrol 2004;61(Suppl 1):S31-8.

45. Painter $\mathrm{P}$, Carlson L, Carey $\mathrm{S}$, et al. Low-functioning hemodialysis patients improve with exercise training. Am J Kidney Dis 2000;36:600-8. doi:10.1053/ajkd.2000.16200 